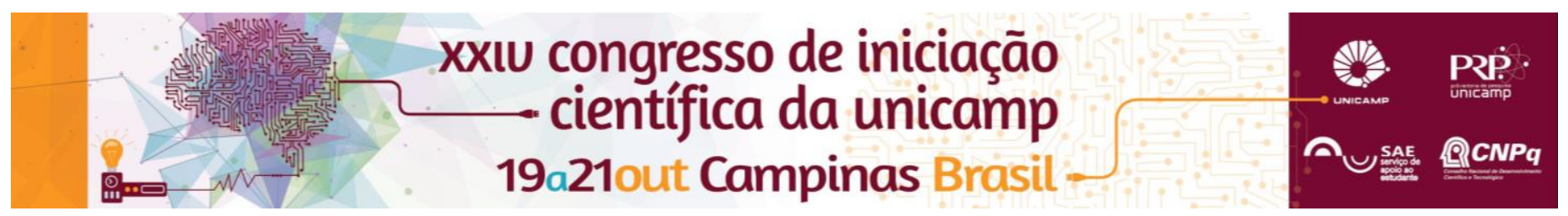

\title{
Definição de bibliotecas de assinaturas espectrais para mapeamento do uso da terra na Microbacia Hidrográfica do Ribeirão Ceveiro, Piracicaba (SP)
}

\section{Leandra Teixeira Marcondes*, Michender Werison Motta Pereira, Mara de Andrade Marinho}

\begin{abstract}
Resumo
A utilização do sensoriamento remoto orbital é reconhecidamente eficiente no mapeamento da vegetação e uso da terra, prestando-se à avaliação temporal das mudanças dos usos das terras e de seus impactos. Este trabalho é parte de pesquisa de doutorado em andamento intitulada "Mapeamento digital de atributos do solo aplicado ao planejamento sustentável do uso da terra na Microbacia do Córrego do Ceveiro, Piracicaba, SP". No contexto do planejamento, a avaliação da adequação do uso atual frente aos usos recomendados pela avaliação de terras traz subsídios ao diagnóstico da sustentabilidade do uso agrícola. O presente trabalho teve por objetivo a definição de bibliotecas de assinaturas espectrais dos usos atuais na microbacia como subsídio à atualização do mapa de vegetação e uso da terra para fins de diagnóstico da adequação do uso.
\end{abstract}

Palavras-chave: Sensoriamento remoto, Curva espectral, Mapeamento digital.

\section{Introdução}

Com o desenvolvimento da ciência da computação e das geotecnologias hoje se dispõe de eficientes ferramentas para monitoramento ambiental. Sistemas de informação geográfica (SIGs) e de posicionamento global (DGPS), produtos do sensoriamento remoto e proximal, modelos digitais de elevação permitem elaborar mapas com maior precisão e acurácia (Valladares, 2012). A utilização de sensoriamento remoto orbital no mapeamento da vegetação e do uso da terra é bastante eficiente, prestando-se também à avaliação temporal das mudanças de uso das terras e de seus impactos. Este trabalho tinha como objetivo definir bibliotecas de assinaturas espectrais dos usos da terra na Microbacia Hidrográfica do Ribeirão Ceveiro para fins de mapeamento do uso atual das terras. Contudo, foi o mesmo interrompido aos seis meses, em virtude da saída da primeira autora para realizar intercâmbio no exterior. Apresentam-se as etapas cumpridas de acordo com o plano de trabalho definido para o primeiro semestre de desenvolvimento do projeto.

\section{Desenvolvimento}

Inicialmente, foi realizado o treinamento para utilização dos programas ArcGIS e Envi, testando composições de bandas, avaliação do georreferenciamento da imagem, aplicação de filtros e contrastes para melhor visualização e interpretação dos alvos. Também foram obtidas as imagens a partir do site http://earthexplorer.usgs.gov/, do Serviço Geológico dos Estados Unidos, procedendo-se à conferência do georreferenciamento a fim de confirmar seu correto posicionamento no espaço. Imagens de Janeiro, Maio e Agosto de 2015 foram selecionadas visando a melhor classificação possível das áreas ocupadas com culturas. O sistema de projeção das imagens foi re-projetado para o sistema SIRGAS 2000. Foram efetuadas viagens de campo para identificar as categorias atuais de uso das terras na microbacia do Ceveiro, georreferenciando as ocorrências com GPS e registrando as feições do terreno com uma câmera digital Nikon Coolpix L330 (Figura 1). Foram identificados e registrados 428 pontos, identificando-se 10 classes de uso, a saber: cana-de-açúcar, pastagem plantada, pastagem natural, cultura anual, reflorestamento, mata, vegetação ciliar, áreas urbanas, represas e mineração.

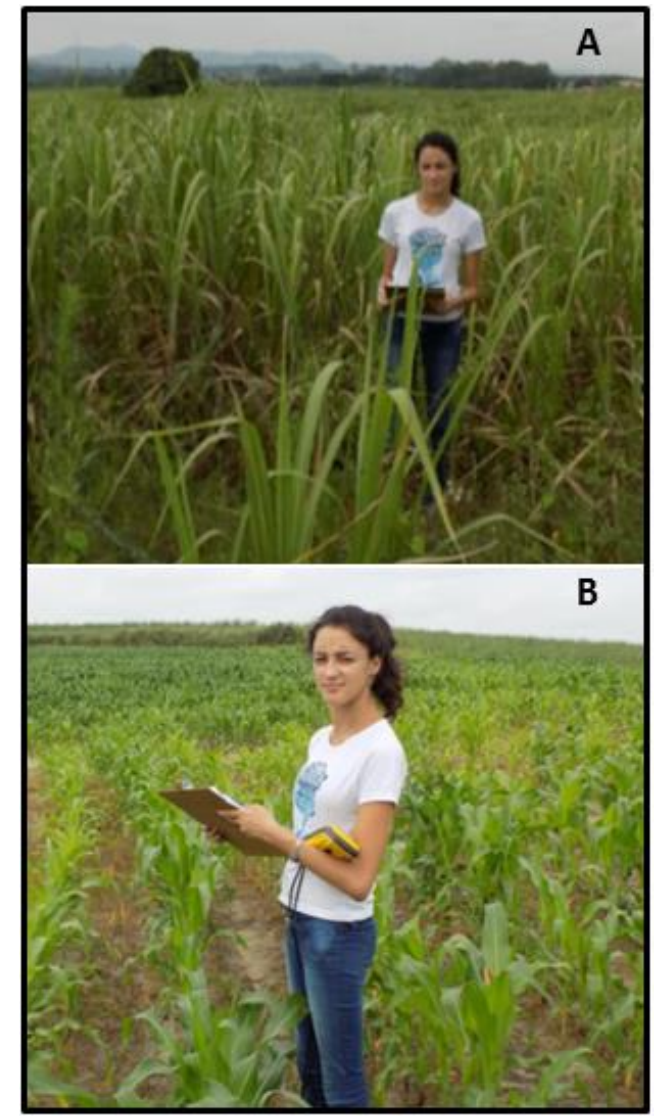

Figura 1. Visita a Microbacia Hidrográfica do Ceveiro para obtenção da "verdade terrestre". Imagens demonstrativas de área de cana de açúcar (A) e de culturas anuais (milho) (B).

Com a saída da primeira autora, o segundo autor deu continuidade aos trabalhos, cujos resultados comporão sua tese de doutorado.

\section{Agradecimentos}

Ao $\mathrm{CNPq} / \mathrm{PIBIC}$, pela bolsa de iniciação científica concedida ao primeiro autor.

${ }^{1}$ VALLADARES, G.S. Geoestatística no mapeamento digital de solos dos tabuleiros costeiros no litoral norte do estado do Ceará. Revista Equador (UFPI), 2012, v.01, n.01, p. 26-43. 